\title{
The Biobank of the "Istituto Zooprofilattico Sperimentale" of Sicily (Italy): an important resource in medical research for safe and quality storage of biological specimens
}

\author{
Annalisa Guercio, Santina Di Bella*, Giusi Macaluso, Patrizia Di Marco, Maria Piazza, Laura Russotto, Stefano \\ Vullo, Francesco Mira \& Giuseppa Purpari
}

Istituto Zooprofilattico Sperimentale della Sicilia “A. Mirri” Via G. Marinuzzi 3, 90129 Palermo, Italy

"Corresponding author, e-mail: santinadibella78@gmail.com

ABSTRACT

KEY WORDS
The "Biobanca del Mediterraneo" (BBM) has been recently developed at the Istituto Zooprofilattico Sperimentale (IZS) of Sicily in Palermo, with the aim to collect and store under standard conditions and in a centralized system several types of certified animal and zoonotic biological resources (bacterial and viral strains, parasites, nucleic acids, positive/negative sera, cell cultures, tissues) in accordance to Quality System procedures as regulated by UNI CEI EN ISO/IEC 17025:2018. Presently, biological material from the OIE Reference Laboratories and National Reference Centres of the IZS of Sicily are being stored. Before storage, selection and cataloging of the most representative biological material collected from the Institutes' laboratories is performed. The "Biobanca del Mediterraneo", together with four other IZSs (IZS Emilia Romagna e Lombardia, IZS Piemonte, Liguria e Valle d'Aosta, IZS Venezie e IZS Abruzzo e Molise), is part of the Network of "Biobanche Veterinarie", recognised as "OIE Collaborative Center for Veterinary Biological Biobank" by the "Office International des Epizooties" (OIE). The objectives of the Biobank are the promotion and implementation of collaborations with the scientific community in order to harmonize and standardize biobanking practices and the development of scientific and technological research to provide services to both the scientific and business world. In fact, collected samples can be used for diagnosis, research, vaccine and drug production, epidemiological studies and other applications.

Received 28.11.2019; accepted 19.12.2019; published online 20.12.2019

Proceedings of the 4th International Congress on Biodiversity "Man, Natural Habitats and Euro-Mediterranean Biodiversity", November 17th-19th, 2017 - Malta

\section{INTRODUCTION}

The "Biobanca del Mediterraneo" has been recently developed at the Istituto Zooprofilattico Sperimentale (IZS) of Sicily in Palermo, with the aim to collect and store under standard conditions and in a centralized system several types of certified animal and zoonotic biological resources in accordance to
Quality System. Since 2014, the "Biobanca del Mediterraneo" together with other 4 II.ZZ.SS. (IZS Emilia Romagna e Lombardia, IZS Piemonte, Liguria e Valle d'Aosta, IZS Venezie, IZS Abruzzo e Molise), is part of the Network of "Biobanche Veterinarie" (Bontempi et al., 2019). Up to now, biological material from the OIE Reference Laboratories (Babesiosis; Theileriosis; Leishmaniosis, Contagious 
agalactia) and the National Reference Centres (C.R.A.Ba.R.T.: Anaplasma, Babesia, Rickettsia, Theileria; C.Re.N.A.: Anisakiasis; Ce.Tox.: Toxoplasmosis; C.Re.Na.L.: Leishmaniosis; C.Re.Ta.M.: Wellbeing, Monitoring and Diagnosis of Diseases of Sea Turtles) of the IZS of Sicily (Fig. 1) have been stored. The storage activity is implementing thanks to the selection and cataloging of the most representative biological materials collected from the laboratories of the Institute and destined, for their intrinsic characteristics, to enrich the Biobank.

The main goals of the BBM are:

- adopt and maintain in the processes an effective Quality Management System, in products, in services, in compliance with the prescriptive requirements of the regulations and with any and other requirements that BBM decides to endorse;

- ensure the resource availability, the necessary information and knowledge for the operation and control of processes, through regular training activities aimed at informing employees of the relevance and importance of their activities and the ways to achieve the objective;

- understand and strengthen the relationship with customers and other stakeholders, improving their level of satisfaction through products and services in line with expectations;

- standardization of storage times of different "biological resources" and their traceability;

- improving the quality of the stored "Biological resources" according to the OIE guidelines;

- select and qualify the products suppliers and services that have an impact on the final quality processes and products, in the achievement of the company's objectives;

- identify the needs of new technological innovation to develop new services and processes according to the expectations of the scientific community;

- draw up an online easy and accessible catalogue for all interested parties;

- endorse the Memoranda of Understanding to comply with the original intellectual property and availability of use;

- carry out all assessments on the basis of objective evidence and in compliance with the rules and regulations in use.

The Managment of the Biobanca del Mediterraneo is committed to implementing and maintaining a quality policy for output quality services of: conservation of biological material and related data, best defined as "biological resources", transfer of "biological resources", production of certified reference materials. In order to achieve and maintain its objectives over time, BBM adopts a quality management system complying with the UNI EN ISO 9001. The criteria of "biological resources" stored in BBM respect the system and test procedures in accordance with ISO/IEC 17025 (General requirements for the competence of testing and calibration laboratories).

\section{MATERIAL AND METHODS}

Numerous matrices (bacteria, nucleic acids, parasites, positive/negative sera, stem cells, anatomical

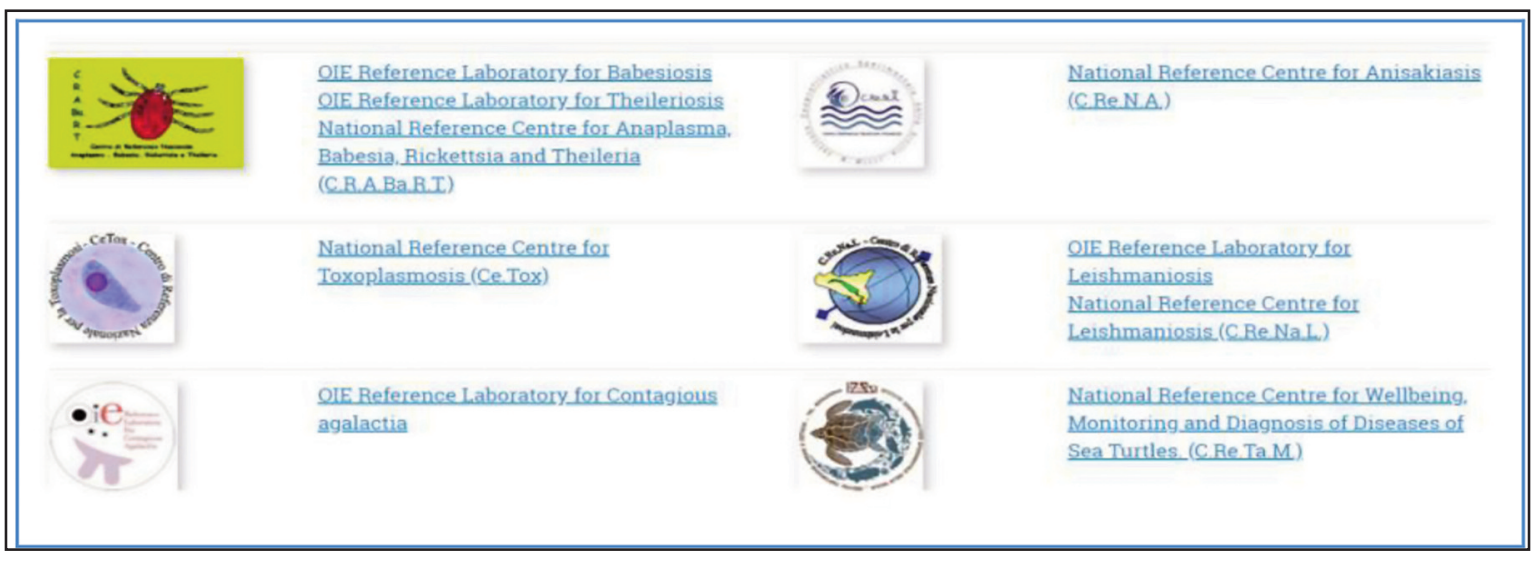

Figure 1. The OIE Reference Laboratories and the National Reference Centres of the IZS of Sicily. 
specimens) were collected and stored in order to be shared with scientific community. All the samples were checked according to UNI CEI EN ISO/IEC 17025:2018 to ensure their identity, quality and purity (Di Bella et al., 2018; Di Marco et al., 2010). Before storage, selection and cataloging of the most representative biological material collected from the laboratories of IZS were performed. All resources were accompanied by the following documents: Safety Data Sheet, Recovery Sheet, Certificate of Analysis containing product identification, qualitative and quantitative traits, reference to the used analytical method, and signature of the director, Dangerous Goods Declaration. Users interested in biological resources stored in the biobank can search the material of interest in the BBM catalogue selecting the material's code to download the technical sheet. The material may be requested and obtained after completion of the Material Transfer Agreement (MTA). The web site dedicated to the Biobanca del Mediterraneo is in continuous development and updating (Fig. 2).

\section{RESULTS}

From 2014 to 2016, IZS of Sicily has stored about 50 specimens. An identification sheet accompanied each sample with all the data concerning quality controls and biosecurity. Currently all information on samples stored in biobank are available at the BBM site (www.bbmed.it). Visiting the website it is possible to know the number of available samples, their origin, laboratory of preparation/isolation and temperature of storage.
The BBM included some of the most modern technological systems for the continuous maintenance and monitoring of the temperature of conservation to $-20,-80,-196^{\circ} \mathrm{C}$, a video surveillance systems and access control. Electronic systems ensure the verification of the optimal environmental parameters for best environmental performance and personnel safety.

Biobank activity is in continuous enrichment because new biological resources will be included in its biorepository.

\section{DISCUSSION AND CONCLUSIONS}

Biobank tasks regard the collection and sharing of bio-specimens with well defined features and associated data (Botti et al., 2008; De Paoli, 2005; Henny, 2003; Lombardo et al., 2015; Quinlan et al., 2015; Regulations European Biobank Maastricht, 2003; Vaught et al., 2011), but also the storage of biological material for the study and the protection of biodiversity (Costa et al., 2018) (Fig. 3). Indeed BBM has specific storage areas for the collection of genetic material from flora and fauna and it also offers medium- and long-term storage services to third parties.

The objectives of the Biobank are the promotion and implementation of collaborations with the scientific community in order to harmonize and standardize bio-banking practices, according to international OIE guidelines and the development of scientific and technological research to provide services to both the scientific and business world. In fact, collected samples can be used for diagnosis,

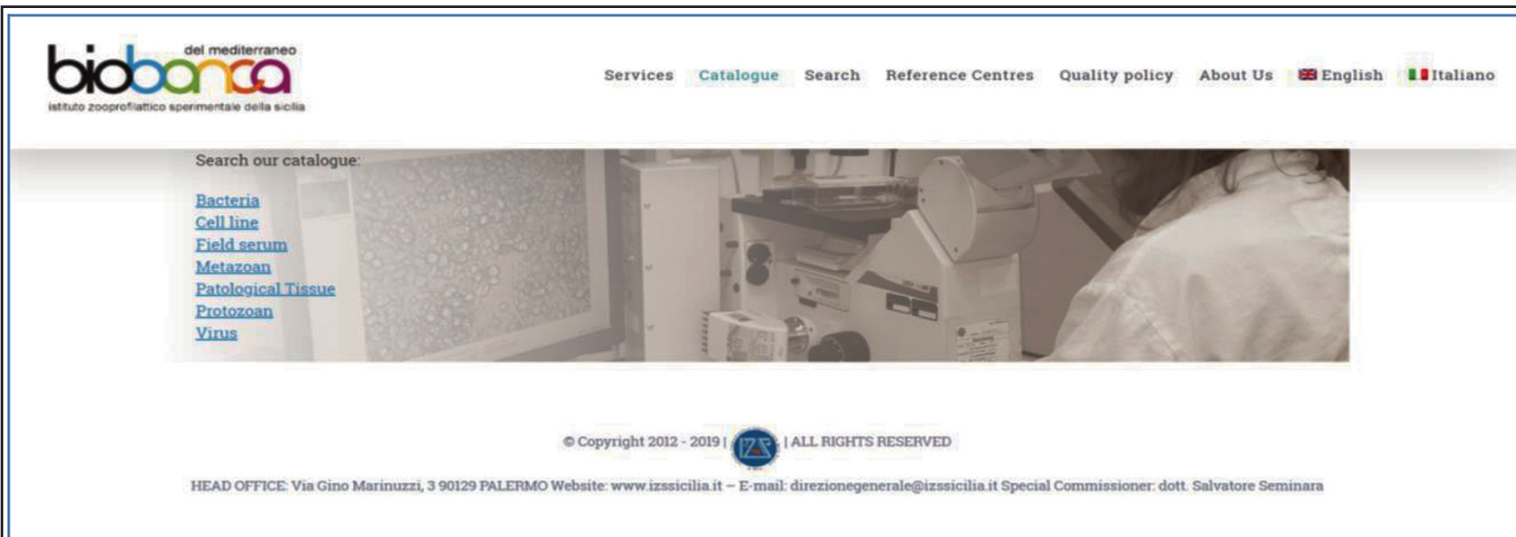

Figure 2. Page of the Biobanca del Mediterraneo website dedicated to the catalog. 


\section{bidbơnca}

Biodiversity is the variety of life forms (plants, animals, microorganisms and ecosystems to which they all belong.) of our Earth, results of long and complex evolutionary processes.

Dersity is not a luxury, but essential to ensuring our future.

Dorks to safeguard the species at risk of extinction through cryopreservation of genetic resources, to ensure
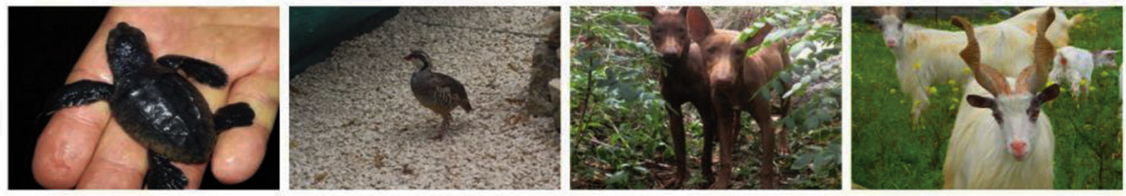

D Copyright 2012-2019

IALL RIGHTS RESERVED

HEAD OFFICE Via Gino Marinuzzi, 390129 PALERMO Website www. izssicilia it - E-mail:direzionegenerale@izssiciliait Special Commissioner dott Salvatore Seminara

Figure 3. Page of the Biobanca del Mediterraneo website dedicated to the storage of biological material for the study and the protection of biodiversity.

research, vaccine and drug production, epidemiological studies and other applications. The "Biobanca del Mediterraneo" represent an unique structure throughout Southern Italy and thank to its potentiality to develop scientific research and technological innovation could become an international reference center (Guercio et al., 2008).

\section{REFERENCES}

Bontempi G., Villa R., Beato M.S., Casalone C., Mazza M., Iulini B., Campanella C., Razzuoli E., Modesto P., Guercio A., Di Marco P., Tittarelli M., Caporale M., Ferrari M., Bonioti M.B. 2019. The Italian Biobank of Veterinary Resources. Congress Proceedings ECCO - XXXVIII Annual Meeting of the European Culture Collection Organisation.

Botti G., Franco R. \& Carbone A., 2008. Sample conservation: freezing, fixation and quality control. Pathologica, 100: 76-85.

Costa A., Graci S., Cammilleri G., Buscemi M.D., Collura R., Vella A. \& Ferrantelli V., 2018. Molecular Identification of Hysterothylacium spp. In: Fishes From the Southern Mediterranean Sea (Southern Italy). Journal of Parasitology, 104: 398-406. https:// doi.org/10.1645/16-60.

De Paoli P., 2005. Bio-banking in microbiology: from sample collection to epidemiology, diagnosis and research. FEMS Microbiol Reviews, 29: 897-910. https://doi.org/10.1016/j.femsre.2005.01.005

Di Bella S., Cannella V., Di Marco P., Piazza M., Purpari G., Di Bella G., Russotto L., Guercio A. Biobanking of canine adipose-derived mesenchymal stem cell (cAD-MSC) for clinical application: a preliminary study of the effect after 7 years long cryopreservation on stemness features. Congress Proceedings GISM Annual Meeting 2018.

Di Marco P., Ferrari M., Sesso L., Purpari G., Russotto L., Di Bella S. \& Guercio A., 2010. Quality controls on Animal Mesenchymal Stem Cells (MSCs). Congress Proceedings ISBER Annual Meeting \& Exhibits 2010.

Guercio A., Purpari G., Loria G.R., Ferrantelli V. \& Caracappa S., 2008. The veterinary and human Biobank in the middle of the mediterranean. Congress Proceedings ISBER Annual Meeting \& Exhibits 2008.

Henny J., 2003. Constitution of a bank of biological material. Practical aspects. Revue d Épidémiologie et de Santé Publique, 51: 127-136.

Lombardo T., Dotti S., Villa R., Cinotti S. \& Ferrari M., 2015. Veterinary biobank facility: development and management for diagnostic and research purposes. Methods in Molecular Biology, 1247: 43-60. https://doi.org/10.1007/978-1-4939-2004-4_4.

Quinlan P.R., Gardner S., Groves M., Emes R. \& Garibaldi J., 2015. A Data-Centric Strategy for Modern Biobanking. Advances in Experimental Medicine and Biology, 864: 165-169. https://doi.org/10.1007/ 978-3-319- 20579-3_13

"Regulations European Biobank Maastricht", 2003. Dr. F.F. Stelma, Dept. Epidemiology, Maastricht University, Jan. 2003.

Vaught J.B. \& Henderson M.K, 2011. Biological sample collection, processing, storage and information management. IARC Scientific Publication, 163: 23-42. 